\title{
Feasibility of short-term fermentation for short-chain fatty acids production from waste activated sludge at initial pH10: Role and significance of rhamnolipid
}

\author{
Zhang-Wei He ${ }^{\mathrm{a}}$, Chun-Xue Yang ${ }^{\mathrm{a}}$, Ling Wang ${ }^{\mathrm{a}}$, Ze-Chong Guo ${ }^{\mathrm{a}}$, Ai-Jie Wang ${ }^{\mathrm{a}, \mathrm{b}, *}$, Wen-Zong Liu ${ }^{\mathrm{b}, *}$ \\ ${ }^{a}$ State Key Laboratory of Urban Water Resource and Environment, Harbin Institute of Technology (SKLUWRE, HIT), 202 Haihe Road, Harbin 150090, China \\ ${ }^{\mathrm{b}}$ Key Laboratory of Environmental Biotechnology, Research Center for Eco-Environmental Sciences, Chinese Academy of Sciences, 18 Shuangqing Road, Haidian District, \\ Beijing 100085, China
}

\section{H I G H L I G H T S}

- Short-term fermentation for SCFAs production from WAS had been proposed.

- RL pretreatment enhanced WAS hydrolysis/acidification under alkaline conditions.

- Role and significance of EPSs had been investigated.

- The cumulative SCFAs were better fitted with pseudo-first-order kinetic model.

- RL + initial pH 10 caused positive synergies on anaerobic fermentation process.

\section{A R T I C L E I N F O}

\section{Article history:}

Received 11 September 2015

Received in revised form 23 December 2015

Accepted 6 January 2016

Available online 22 January 2016

\section{Keywords:}

Rhamnolipid

Waste activated sludge

Short-chain fatty acids

Alkaline anaerobic fermentation

Extracellular polymeric substances

Pseudo-first-order model

\begin{abstract}
A B S T R A C T
Short-chain fatty acids (SCFAs), preferred carbon source for enhanced biological nutrients removal system, can be produced from anaerobic fermentation of waste activated sludge (WAS). Hydrolysis is known as the rate-limiting step for SCFAs production. This study presents a novel technology using rhamnolipid (RL) pretreatment connected alkaline anaerobic fermentation to enhance SCFAs production. Experiment results showed that the integration treatments performed significant enhancement of SCFAs production, and the fermentation time was remarkably shortened. The maximum SCFAs production, $378 \mathrm{mg}$ COD/g VSS (volatile suspended solid), reached at 72-h fermentation time under $0.2 \mathrm{~g} \mathrm{RL} / \mathrm{g}$ TSS (total suspended solid) and initial pH 10 treatment, which was 4.31,1.32 and 1.24 times higher than that of control, initial pH 10 and $0.2 \mathrm{~g} \mathrm{RL} / \mathrm{g}$ TSS treatment, respectively. The mechanism study showed that integration treatments could enhance the release of constituents from the cells and/or extracellular polymeric substances to suspension, and hydrolysis rate constant was improved greatly in integration treatment, 8.68, 2.14 and 1.55 times higher than that of control, sole RL and initial pH 10 treatments, respectively. The results suggested that positive synergy led to improvement of WAS solubilization and SCFAs production under integration conditions. The pseudo-first-order model was successfully built to present the SCFAs accumulation. Therefore, the integration method in this work was a promising technology for SCFAs production enhancement from WAS.
\end{abstract}

(c) 2016 Elsevier B.V. All rights reserved.

\section{Introduction}

The enhanced biological nutrients removal system has been widely employed to treat wastewater all over the world. However,

\footnotetext{
* Corresponding authors at: State Key Laboratory of Urban Water Resource and Environment, Harbin Institute of Technology (SKLUWRE, HIT), 202 Haihe Road, Harbin 150090, China. Tel./fax: +86 45186282195 (A.-J. Wang). Tel./fax: +86 451 86282110 (W. Liu).

E-mail addresses: waj0578@hit.edu.cn (A.-J. Wang), wzliu@rcees.ac.cn (W.-Z. Liu).
}

the available biodegradable chemical oxygen demand (COD) contained in influent, cannot meet the carbon source (CS) demand for both denitrifying bacteria and phosphorous accumulating organisms $[1,2]$. It is unambiguous that the chemically synthesized CS (e.g., acetate, propionate and glucose) serving as the external CS is neither cost-effective nor sustainable in full scale wastewater treatment plant (WWTP) [3,4]. Recently, some literatures have reported the feasibility of fermentation liquid (enriched in shortchain fatty acids (SCFAs)) from waste activated sludge (WAS) as the external CS for nutrients removal, and satisfactory results were achieved [3-6]. 
As the by-product of WWTPs, 6.25 million tons dry sludge has been produced in China in 2013 and is still showing a rapid increasing rate [7]. The WAS disposal has been considered as a main issue for the sustainable development of WWTPs, because the cost of efficient WAS disposal is very high, accounting for approximately $40-60 \%$ operation fee of WWTPs [7-9]. As well known, the main component of WAS is organic matter (e.g., proteins, polysaccharides and lipid), which makes it be a potential substrate for SCFAs production [10,11]. Currently, many studies have proved the feasibility of SCFAs production from WAS with anaerobic digestion process [11-18]. Generally, anaerobic digestion process of particulate organic matters (POMs) usually includes three stages: hydrolysis, acidification and methanogenesis $[19,20]$. Hydrolysis is known as the rate-limiting step, only little of total COD (TCOD) of WAS can be biodegraded unless the POMs are significantly solubilized [21-24]. Aiming to strengthen the performance of anaerobic digestion of WAS, some efforts have been developed, such as chemical, mechanical, biological, thermal co-fermentation treatments [7,19,20,24-26]. Alkaline, one of chemical pretreatment, has been selected as a potential way for improving SCFAs production [7,17,24,27]. On one hand, this method can not only enhance the performance of WAS hydrolysis but also inhibit the activities of methanogens, which results in positive effects on SCFAs production $[17,27]$. On the other hand, it is cost-effective and operation-convenient, which is of great strategic significance. However, though the SCFAs production can be improved at $\mathrm{pH} 10$, more than $60 \%$ of volatile suspended solids (VSS) could not be effectively degraded by microorganisms $[27,28]$. Thus, it is necessary to couple alkaline with other methods to further harvest improvement of SCFAs production from WAS.

Recently, some researchers have reported that bio-surfactant can accelerate the rate of sludge hydrolysis, and benefit to SCFAs production by improving POMs dissolution and inhibiting methanogenesis $[12,13,21]$. Though the chemically synthesized surfactants (e.g., sodium dodecyl sulfate and sodium dodecyl benzenesulfonate) can improve the efficiency of anaerobic fermentation of WAS, their addition and residual present a potential risk to the ecosystem because of biotoxicity in an accumulated concentration [12,21]. Rhamnolipid (RL), as a kind of biosurfactants, is eco-friendly, this makes it a desirable replacement of traditionally chemical surfactants. It has been proved that RL can be produced in situ by some microorganisms, such as Pseudomonas, during WAS anaerobic fermentation [12,21]. And an external addition of RL can trigger this self-synthesis process. In our previous study, we have found that RL pretreatment effectively enhanced SCFAs production, meanwhile, RL concentration in liquid phase at 96-h fermentation time was 1.49 -fold higher than that at the beginning fermentation time, which proved that RL generated in situ, and further contributed to WAS hydrolysis and acidification [21]. Thus, RL pretreatment method is a promising technology for WAS treatment because it is eco-friendly, renewable and cost-effective, and may be coupled with alkaline method successfully for further enhancing WAS dissolution and acidification.

The main objective of this study is to evaluate the feasibility of RL pretreatment integrated into alkaline anaerobic fermentation for enhancing SCFAs production from WAS. The mechanisms of proposed method for enhancing SCFAs production from WAS were explored by analyzing extracellular polymeric substances (EPSs) and kinetic models of WAS hydrolysis. Meanwhile, the mathematical models were also built to better understand the kinetics of SCFAs accumulation. The outcome of this work may have potential application to solve the CS shortage of a WWTP by a cost-effective and renewable way.

\section{Materials and methods}

\subsection{Source of WAS and bio-surfactant RL}

The WAS was taken from the secondary sedimentation tank of Taiping Municipal Wastewater Treatment Plant, running with anae robic-anoxic-aerobic $\left(\mathrm{A}^{2} / \mathrm{O}\right)$ system, Harbin, China. The WAS firstly was thickened by gravitational sedimentation for $24 \mathrm{~h}$ at $4{ }^{\circ} \mathrm{C}$, then screened with a $1 \mathrm{~mm}$ sieve to remove impurities, finally stored at $4{ }^{\circ} \mathrm{C}$ prior for later use and test. And the main characteristics of WAS were: pH $6.51 \pm 0.02$, total suspended solid (TSS) $23.577 \pm 0.487 \mathrm{~g} / \mathrm{L}, \quad$ VSS $14.425 \pm 0.428 \mathrm{~g} / \mathrm{L}$, total COD (TCOD) $22,711 \pm 500 \mathrm{mg} / \mathrm{L}$, soluble COD (SCOD) $231 \pm 34 \mathrm{mg} / \mathrm{L}$, soluble proteins $114 \pm 15 \mathrm{mg} \mathrm{COD} / \mathrm{L}$, soluble polysaccharides $41 \pm 8 \mathrm{mg}$ COD/L, and SCFAs $86 \pm 22 \mathrm{mg} \mathrm{COD/L}$

The bio-surfactant RL was purchased from Victex Company, China, and the purity was $80 \%$, which was a blend of $\mathrm{RhaC}_{10} \mathrm{C}_{10}$ $\left(\mathrm{C}_{26} \mathrm{H}_{48} \mathrm{O}_{9}, \mathrm{~m} / \mathrm{z} 503\right)$ and RhaRhaC ${ }_{10} \mathrm{C}_{10}\left(\mathrm{C}_{32} \mathrm{H}_{58} \mathrm{O}_{13}, \mathrm{~m} / \mathrm{z}\right.$ 649), shown in Fig. S1.

\subsection{Batch experiments for SCFAs production}

To investigate the effects of the sole RL and RL and initial $\mathrm{pH}=10$ on SCFAs production from WAS, two groups of experiments were carried out (Table 1). Group 1 was to investigate the effects of sole RL levels on SCFAs production. And group 2 was employed to explore the effects of RL pretreatment integrated into alkaline anaerobic fermentation on SCFAs production. The demanded $\mathrm{pH}$ achieved by adding $4 \mathrm{M} \mathrm{NaOH}$ and $1 \mathrm{M} \mathrm{HCl}$. Batch laboratory-scale anaerobic fermentation experiments were conducted in $500 \mathrm{~mL}$ serum bottles filled with $300 \mathrm{~mL}$ raw WAS each. Nitrogen gas was introduced to the reactors for $10 \mathrm{~min}$ to remove oxygen, then the reactors were capped, sealed, and stirred in an air-bath shaker $(100 \mathrm{rpm})$ at $35 \pm 1^{\circ} \mathrm{C}$ for 5 days. All the fermentation experiments were carried out in triplicate.

\subsection{EPSs extraction}

Microbial EPSs are the main components of the WAS floc matrix $[29,30]$, and their presences are of great importance for maintaining the functional integrity and strength of sludge as well as biodegradability [31], so the changes of their characteristics are of great concern to understand the effects of pretreatment methods on WAS hydrolysis and further SCFAs production. The EPSs had been divided into two parts, including loosely bound EPSs (LB-EPSs) and tightly bound EPSs (TB-EPSs) [29,32]. The extraction methods of LB-EPSs and TB-EPSs referenced from the previous literatures [29,32], and were modified appropriately. The specific method was as follows: firstly, $10 \mathrm{~mL}$ samples were centrifuged at $4000 \mathrm{~g}$ for $10 \mathrm{~min}$, the supernatant was filtered with $0.45 \mu \mathrm{m}$ cellulose nitrate membrane filters, and the filtrate was considered

Table 1

Batch experiments for SCFAs production from WAS.

\begin{tabular}{lrlr}
\hline Group & No. & $\begin{array}{l}\text { RL additions }(\mathrm{g} / \mathrm{g} \\
\text { TSS })\end{array}$ & $\mathrm{pH}$ \\
\hline 1. Effects of RL addition levels & 1 & 0 & $6.51 \pm 0.02$ \\
& 2 & 0.025 & $6.51 \pm 0.02$ \\
& 3 & 0.05 & $6.51 \pm 0.02$ \\
& 4 & 0.1 & $6.51 \pm 0.02$ \\
2. Effects of RL and initial & 5 & 0.2 & $6.51 \pm 0.02$ \\
pH =10 & 6 & 0 & $10.08 \pm 0.04$ \\
& 7 & 0.025 & $10.03 \pm 0.04$ \\
& 8 & 0.05 & $10.02 \pm 0.01$ \\
& 9 & 0.1 & $10.03 \pm 0.02$ \\
& 10 & 0.2 & $10.03 \pm 0.01^{\prime}$ \\
\hline
\end{tabular}


as the dissolved organic matters (DOMs). Then, the residue was treated by the EPSs extraction method for LB-EPSs [29], and the filtrate was serviced as the LB-EPSs. Finally, after LB-EPSs extraction, the residue was treated according to the EPSs extraction method for TB-EPSs [29], and the filtrate was regarded as the TB-EPSs.

\subsection{Analytical methods}

Sludge samples collected from reactors were centrifuged at $10,000 \mathrm{rpm}$ for $10 \mathrm{~min}$, then supernatant samples were filtered by $0.45 \mu \mathrm{m}$ cellulose nitrate membrane filters and finally filtrated samples were stored at $4{ }^{\circ} \mathrm{C}$ prior to analysis. The filtrate was immediately used to analyze SCFAs, polysaccharides, and proteins. The measurements of SCFAs, SCOD, TCOD, polysaccharides, proteins, TSS, VSS and $\mathrm{pH}$ were the same as the methods mentioned in our previous publications $[11,14,21,33]$. The SCFAs were regarded as the sum of acetic (HAc), propionic (HPr), n-butyric (n-HBu), iso-butyric (iso-HBu), n-valeric (n-HVa), and iso-valeric acids (iso-HVa) [11,33,34].

Three-dimensional fluorescence excitation-emission matrix (EEM) spectroscopy (FP-6500, Jasco, Tokyo, Japan) was applied to characterize the DOMs, LB-EPSs, and TB-EPSs extracted from raw sludge, and WAS after sole RL $=0.1 \mathrm{~g} / \mathrm{g}$ TSS, initial $\mathrm{pH}=10$ and initial $\mathrm{pH}=10$ and $0.1 \mathrm{~g} \mathrm{RL} / \mathrm{g}$ TSS treatments. Details of spectra scan, elimination of inner filtering effect and Raman scattering, and parallel factor analysis (PARAFAC) were used to model EEM fluorescence data, could be found in our previous publication $[11,14,33]$.

\subsection{Kinetic modeling}

Two kinetic models (pseudo-first-order (PFO), pseudo-secondorder (PSO)) were applied to understand both the effects of fermentation time and kinetic behavior on WAS hydrolysis and SCFAs production. The PFO model assumed that the rate of WAS hydrolysis and SCFAs accumulation with fermentation time was directly proportional to the differences between the relative equilibrium capacity of SCOD/SCFAs and the amount of SCOD/SCFAs at any time $t$, respectively. The PFO model could be determined by the following equation [35]:

$\ln \left(q_{e}-q_{t}\right)=\ln q_{e}-k t$

where $q_{t}(\mathrm{mg} \mathrm{COD} / \mathrm{L})$ were the amount of SCOD/SCFAs at time $t(\mathrm{~h})$, $q_{e}(\mathrm{mg} \mathrm{COD} / \mathrm{L})$ were the relative equilibrium capacity of SCOD/ SCFAs, and $K_{1}\left(\mathrm{~h}^{-1}\right)$ was the rate constant of PFO model. As the accumulation of SCOD/SCFAs depended on their rates of production and consumption, here, the specific equilibrium capacity of SCOD/ SCFAs were defined as the increased SCOD/SCFAs, caused by the hydrolysis/acidification of particulate organic matters, were approximately equal to the decreased SCOD/SCFAs, caused by biodegradation such as gasification [36].

The PSO model assumed that the SCFAs accumulation rate was proportional to the square of the driving force [37]. The PSO model could be expressed by the following equation [35]:

$\frac{1}{q_{t}}=\frac{1}{k_{2} q_{e}^{2}}+\frac{t}{q_{t}}$

where $k_{2}$ was the rate constant of PSO model, L/(mg COD h).

The normalized standard deviation (NSD, $\Delta q(\%)$ ) and the average relative error (ARE $(\%)$ ), calculated by the following Eqs. (3) and (4), were employed to evaluate the error of both PFO and PSO models $[38,39]$ :

$\operatorname{ARE}(\%)=\frac{100}{N-1} \sum_{i=1}^{N}\left(\frac{q_{t, \exp }-q_{t, c a l}}{q_{t, \exp }}\right)_{i}^{2}$
$\Delta q(\%)=100 \sqrt{\frac{1}{N-1} \sum_{i=1}^{N}\left(\frac{q_{t, \exp }-q_{t, \mathrm{cal}}}{q_{t, \exp }}\right)_{i}^{2}}$

where $q_{t, \exp }$ and $q_{t, \text { cal }}(\mathrm{mg} \mathrm{COD} / \mathrm{L})$ were the experimental and calculated values, respectively, at time ' $t$ ' and $N$ was the number of measurements made.

\section{Results and discussion}

\subsection{Performance of SCFAs production from WAS}

\subsubsection{Effect of different RL levels on SCFAs production}

SCFAs accumulations under different RL dosages are shown in Fig. S2, it was clear that the control test achieved the minimum SCFAs production at equilibration time, $1263 \mathrm{mg}$ COD/L (i.e., $88 \mathrm{mg}$ COD $/ \mathrm{g}$ VSS). By contrast, the corresponding equilibrium SCFAs production increased with the RL dosage increasing (from $0.025 \mathrm{~g} / \mathrm{g}$ TSS to $0.2 \mathrm{~g} / \mathrm{g}$ TSS). When the RL addition was $0.2 \mathrm{~g} / \mathrm{g}$ TSS, the maximum SCFAs production reached, $4392 \mathrm{mg}$ COD/L (i.e., $304 \mathrm{mg}$ COD/g VSS), which was 3.47 times higher than that of the control test. However, the SCFAs production at dosage $0.2 \mathrm{~g} / \mathrm{g}$ TSS had no significant increase $(p>0.05)$ compared to that (4102 mg COD/L, i.e., $285 \mathrm{mg} \mathrm{COD/g} \mathrm{VSS}$ ) obtained at dosage $0.1 \mathrm{~g} /$ $\mathrm{g}$ TSS (as shown in Fig. S2), indicating that a reduced RL addition to $0.1 \mathrm{~g} / \mathrm{g}$ TSS could be applied to pretreat WAS for SCFAs production. Furthermore, all the RL tests achieved the maximal SCFAs production at 96-h (i.e., 4-day) fermentation time, which was much less than that reported by previous studies, such as 8 days in the research of Yuan et al. [27] and 6 days in the research of Jiang et al. [13], suggested that short-term fermentation for SCFAs production from WAS was possible under RL pretreatment, which was beneficial to both improve the efficiency and reduce the cost of sludge treatment.

\subsubsection{Enhancement of SCFAs production under combination of RL and alkaline treatments}

Previous studies have reported that SCFAs production from WAS could be significantly improved by controlling the anaerobic fermentation $\mathrm{pH}$ at constant 10.0 [27]. The SCFAs production from WAS anaerobic fermentation had been investigated at both initial and constant 10.0 in this work. The equilibrium SCFAs production at initial pH 10 was $4130 \mathrm{mg}$ COD/L (i.e., $287 \mathrm{mg}$ COD/g VSS), which was 3.27 times higher than that obtained in the control test, indicating the potential application of initial pH 10 for SCFAs production from WAS. And the maximum SCFAs production from WAS under a constant $\mathrm{pH}$ of 10 was $4758 \mathrm{mg}$ COD/L (i.e., $330 \mathrm{mg}$ COD/g VSS) at 10-day fermentation time, which was 1.15 times higher than that under initial $\mathrm{pH} 10$. Though a slight improvement of SCFAs production achieved under a constant $\mathrm{pH}$ of 10 compared to under initial $\mathrm{pH} 10$, the fermentation time of the maximum SCFAs accumulation reached was 3.33 times longer, which went against the high efficiency demand of WAS disposal. Moreover, a system continuously kept at $\mathrm{pH} 10$ was neither economic nor convenient because of the continuous acid/alkaline adjustment. Thus, compared with the constant $\mathrm{pH} 10$, initial $\mathrm{pH} 10$ is relatively more efficient, economical and sustainable for SCFAs production from WAS. It was obvious that SCFAs productions were substantially promoted by RL addition, alkaline, and RL and alkaline pretreatment compared with control test (Fig. 1). Meanwhile, it was significant, while using RL to enhance the SCFAs production under initial pH 10 anaerobic fermentation. The maximum SCFAs production achieved under $0.2 \mathrm{~g} \mathrm{RL} / \mathrm{g}$ TSS integrated with initial pH 10 treatment, $5445 \mathrm{mg}$ COD/L (i.e., $378 \mathrm{mg}$ COD/g VSS), which was 4.31 , 1.32 and 1.24 times higher than that of control, initial pH 10 and 

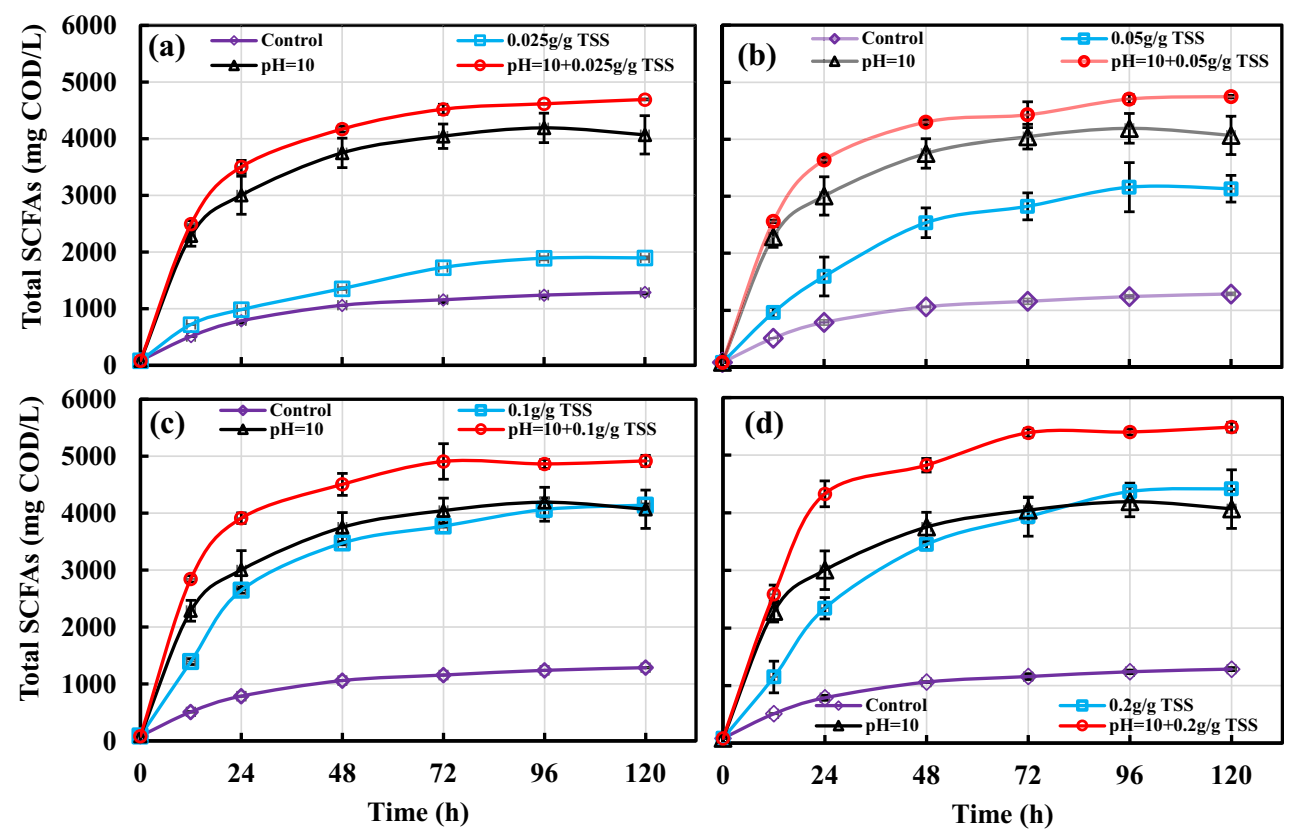

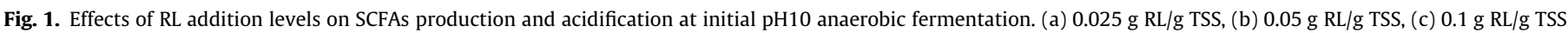
and (d) $0.2 \mathrm{~g} \mathrm{RL} / \mathrm{g}$ TSS

$0.2 \mathrm{~g} \mathrm{RL} / \mathrm{g}$ TSS tests, respectively. Also, the fermentation time of equilibrium SCFAs accumulations reached ( 72 h, i.e., 3 days) in integration tests relatively less than that using sole RL treatment, demonstrating that when the integration methods were employed, the fermentation time could be further shortened. The above results showed that the production of SCFAs could be significantly improved at initial $\mathrm{pH} 10$ and further enhanced under the integration treatment, suggesting that RL pretreatment integrated into alkaline anaerobic fermentation of WAS could result in positive synergies on SCFAs production.

\subsubsection{Composition of SCFAs under different conditions at different fermentation time}

The composition of SCFAs would influence the nutrient removal efficiency, while the fermentation liquid of WAS was used as the external CS for enhanced biological nutrients removal system $[1,6,40]$. It was observed that with fermentation time going on, the composition was significantly affected by the dosages of $\mathrm{RL}$ and $\mathrm{pH}$ (Fig. 2). For all the tests, the two highest individual SCFAs were HAc and HPr, with a total percentage of 47.7-66.9\%, in accordance with the previous studies [11,21,33]. Ordering the average percentage of individual SCFA was HAC > $\mathrm{HPr}>$ iso-HVa $>\mathrm{n}-\mathrm{HBu}>\mathrm{n}-\mathrm{HVa}>\mathrm{i}$ iso-HBu. The possible reasons was that $\mathrm{HAc}, \mathrm{n}-\mathrm{HBu}$ and $\mathrm{HPr}$ were formed directly from the fermentation of polysaccharides and proteins, yet the higher molecular weight SCFA such as n-HVa, were largely relevant to the fermentation of proteins [11]. And $\mathrm{n}-\mathrm{HBu}, \mathrm{HPr}$ and $\mathrm{n}-\mathrm{HVa}$ were easily biodegraded to form HAc in the anaerobic fermentation system $[11,27]$.

Moreover, RL levels had a significant influence on the ratio of HAc to HPr (Fig. 2). For sole RL treatments, under lower RL dosage $(\leqslant 0.05 \mathrm{~g} / \mathrm{g}$ TSS), the ratio of HAc to HPr decreased quickly with fermentation time going on. However, the ratio of HAc to HPr was kept stable in combined treatment of RL and alkaline throughout the fermentation process. It was indicated that an alkaline condition (initial $\mathrm{pH}$ 10) would maintain a stable composition of SCFAs, which preferred to the enhanced biological nutrients removal system while SCFAs were used as the internal CS.

\subsection{Role and significance of EPSs under different pretreatment conditions}

\subsubsection{Organic fractions in EPSs}

As the main components of EPSs were polysaccharides, proteins, and humic acid, etc., especially polysaccharides and proteins, accounted for $50-72 \%$ of EPSs [29], changes of SCOD, soluble polysaccharides, and proteins were used to evaluate the effects of sole RL and integration pretreatments on WAS solubilization. Fig. 3 shows the changes of SCOD, soluble proteins, and polysaccharides in DOMs, LB-EPSs, and TB-EPSs under different conditions at 12-h fermentation time. It was obvious all the pretreatment methods benefited to SCOD increase (Fig. 3(a)). Integration treatments performed better than either sole $\mathrm{RL}$ or initial $\mathrm{pH}=10$ treatments. In the control test, SCOD of DOMs only increased by approximately $540 \mathrm{mg} / \mathrm{L}$. By contrast, SCOD of DOMs rose by approximately $3877 \mathrm{mg} / \mathrm{L}$ under RL dosage $0.2 \mathrm{~g} / \mathrm{g}$ TSS and $3313 \mathrm{mg} / \mathrm{L}$ under initial $\mathrm{pH}=10$ treatments, which were 7.18 and 6.14 times higher than that of control test, respectively. A further increase of SCOD of DOMs was obtained in the case of combined treatment, increasing by $6199 \mathrm{mg} / \mathrm{L}$ (11.48 times higher than control test). The more release of SCOD implied that more microbial cells and/or EPSs became soluble substrates from POMs under different pretreatment conditions [11,14,33]. A similar increasing trend was also observed in the case of soluble proteins and polysaccharides (Fig. 3(b) and (c)). This corroborated the SCOD results, demonstrated more intracellular and/or extracellular constituents were released from the cells and/or EPSs [19,31].

As shown in Fig. 3(a), with RL addition increasing from 0 to $0.2 \mathrm{~g} / \mathrm{g}$ TSS, the SCOD of LB-EPSs was increased from 131 to $918 \mathrm{mg} / \mathrm{L}$ in sole RL treatment, and from 623 to $978 \mathrm{mg} / \mathrm{L}$ in integration treatments. The SCODs of TB-EPSs all decreased, either in sole RL or integration treatment. A similar trends was also observed in the case of soluble proteins and polysaccharides both in LB-EPSs and TB-EPSs (Fig. 3(b) and (c)). This also corroborated the SCOD results.

The intracellular released capacity (IRC) was developed to evaluate the organics release from the cells under different pretreatment conditions. It can be expressed by the following equation: 

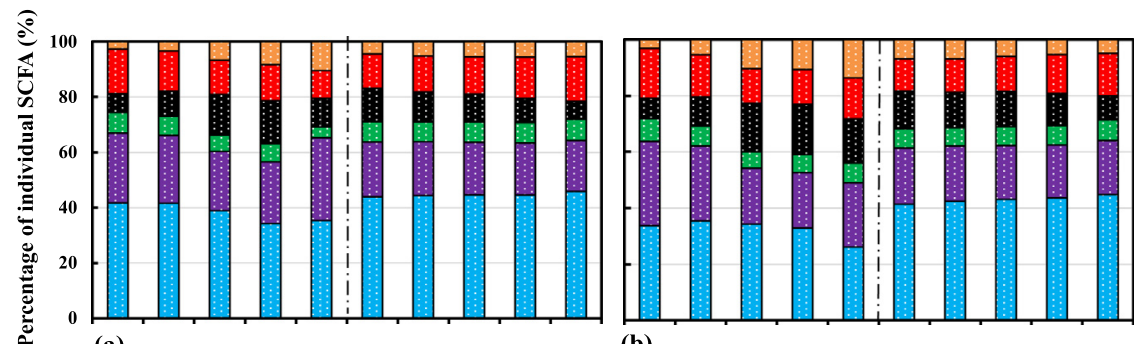

(a)

(b)
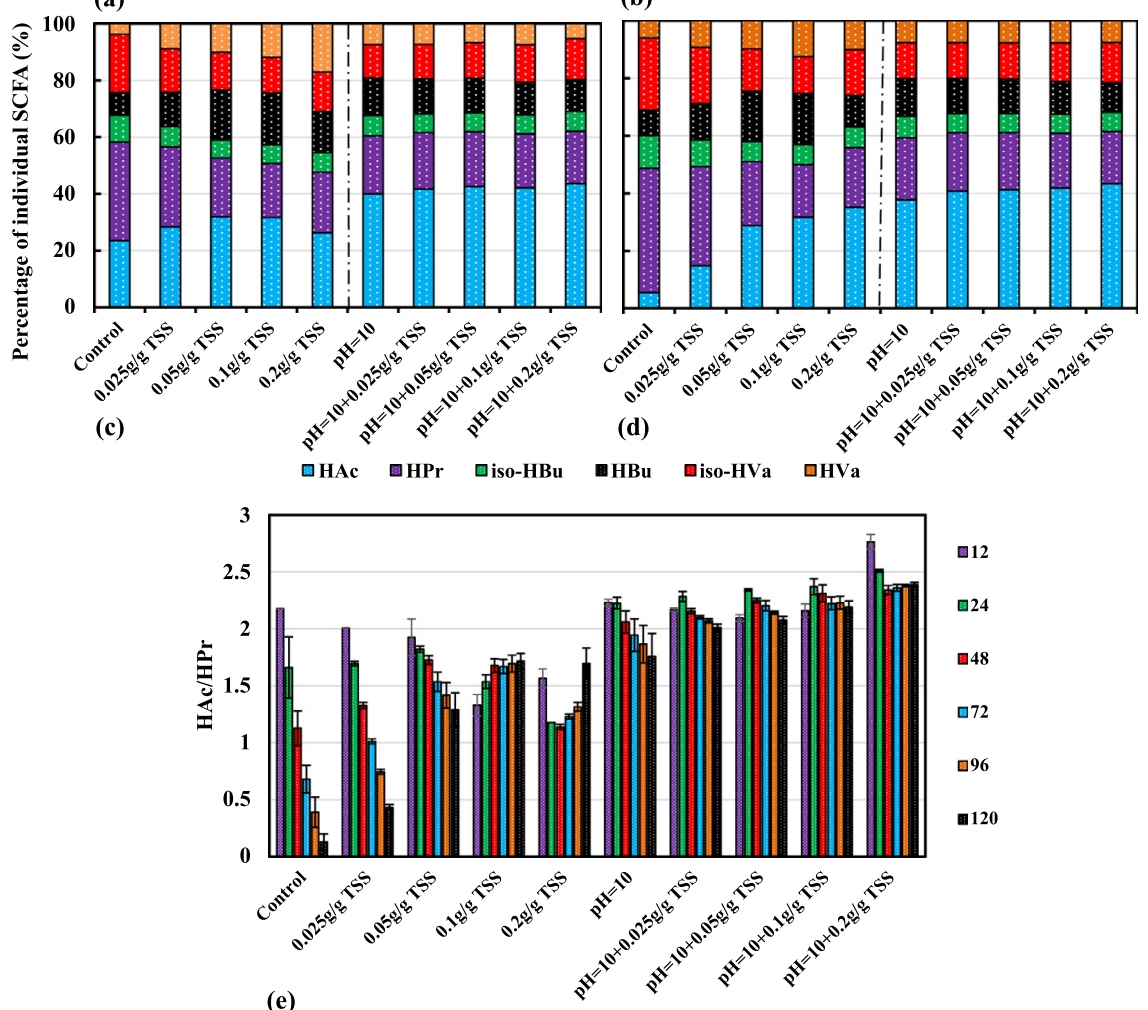

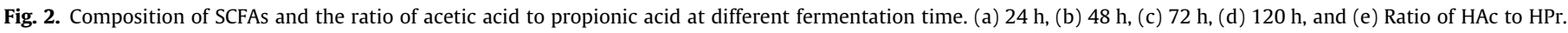

$\mathrm{IRC}=\left(\mathrm{DOM}_{\mathrm{exp}}^{x}-\mathrm{DOM}_{\mathrm{raw}}^{x}\right)-\left(\mathrm{EPSs}_{\mathrm{raw}}^{x}-\mathrm{EPSS}_{\mathrm{exp}}^{x}\right)$

where EPSs $s_{\text {exp }}^{x}$ and EPSs $s_{\text {raw }}^{x}(\mathrm{mg} / \mathrm{L})$ were the sums of SCOD in LB-EPSs and TB-EPSs under different pretreatment conditions at 12-h fermentation time and raw sludge, respectively. $\mathrm{DOM}_{\exp }^{x}$ and $\mathrm{DOM}_{\mathrm{raw}}^{x}$ $(\mathrm{mg} / \mathrm{L})$ were the corresponding SCOD in suspension, respectively. And $x$ was the given experiment No., shown in Table 1 .

As shown in Fig. 3, with RL dosage increasing, IRC increased in both sole RL and integration treatments. For SCOD, the highest IRC obtained at $0.2 \mathrm{~g} \mathrm{RL} / \mathrm{g}$ TSS under sole RL treatments, $4130 \mathrm{mg} / \mathrm{L}$ (11.76 times higher than control). In the integration treatments, the highest IRC obtained under $0.2 \mathrm{~g} \mathrm{RL} / \mathrm{g}$ TSS and initial $\mathrm{pH}=10$ treatment, $5822 \mathrm{mg} / \mathrm{L}$ (16.75 and 1.41 times respectively higher than that of control and sole RL dosage $0.2 \mathrm{~g} / \mathrm{g}$ TSS). A similar trend was also observed in the case of soluble proteins and polysaccharides (Fig. 3(b) and (c)), whose changes contributed to SCOD changes. These above results further demonstrated the positive effects of RL addition on the release of intracellular constituents, and RL integrated into alkaline anaerobic fermentation of WAS could result in positive synergies on organics release from the cells. As SCFAs mainly formed from the fermentation of polysaccharides and proteins [11,27], both sole RL and integration treatments could provide substrates efficiently for WAS anaerobic fermentation to produce SCFAs, but the integration treatment was more efficient.

\subsubsection{EEM fluorescence spectra analysis of EPSs}

Previous studies had reported that three-dimensional EEM could be applied to characterize complete information of some fluorescent substances (such as proteins, metabolites (e.g., amino, fulvic and humic acids), enzymes and pigments) by changing excitation and emission wavelength simultaneously [41,42]. We used EEM spectra to comprehensively reveal the component changes of WAS under different conditions in terms of DOMs, LB-EPSs, and TB-EPSs $[11,14,43,44]$. And the PARAFAC, a chemometric method with three-way decomposition, was employed to separate the spectra of the main components from overlapped EEM spectra [41-44].

Two fluorescence peaks could be identified from the EEM spectra by the PARAFAC (Fig. 4 and Fig. S3). The two peaks were associated with tryptophan (Ex/Em 275/340, named component 1 (Com.1)) and tyrosine (Ex/Em 275/305, named component 2 (Com.2)) protein-like substances, respectively $[11,12,14,42]$. As shown in Fig. 4 and Fig. S3, all the samples were similar in the peak locations with main fluorophore of protein-like substances, but have different fluorescence intensities (FIs) for different pretreatment methods. In DOMs, compared with raw sludge, after 12-h pretreatment time, the FI all increased significantly, especially in experimental tests. The increased fluorescence signals could be attributed to the increase of protein-like substances in WAS mixed liquor $[14,42,43]$. This was consistent with the results of proteins 

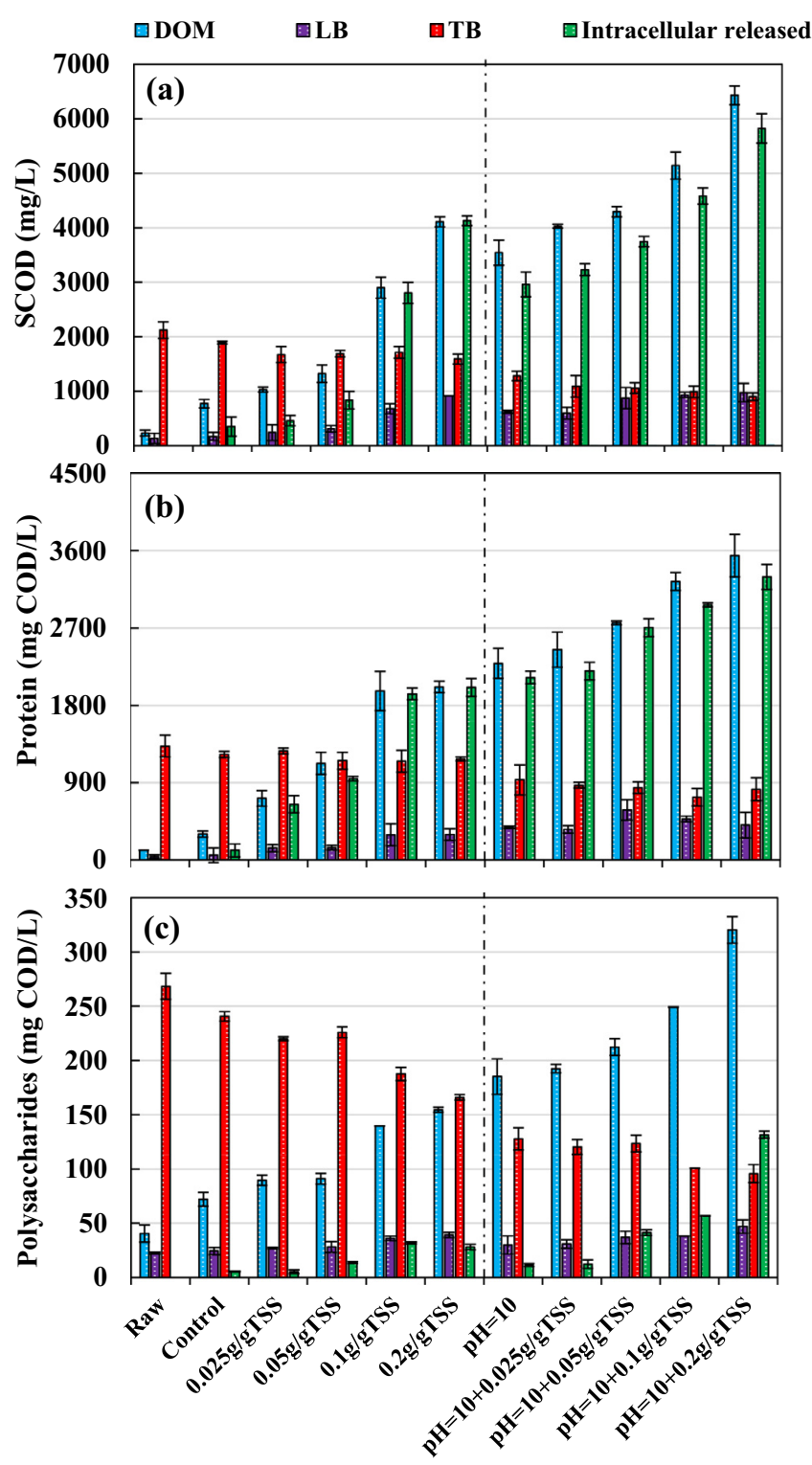

Fig. 3. The changes of SCOD, soluble proteins, and polysaccharides in DOM, LB-EPS, and TB-EPS under different pretreatment conditions at 12 -h anaerobic fermentation time. (a) SCOD, (b) Soluble proteins, and (c) Soluble polysaccharides.

under different conditions (Section 3.2.1). The maximum FI of both Com. 1 and Com.2 were all obtained under the integration treatment, 351 and 450, respectively, which were respectively 1.73 , 2.53 and 15.87 times higher than that of initial $\mathrm{pH}=10$, sole $\mathrm{RL}=0.1 \mathrm{~g} / \mathrm{g}$ TSS, and control tests for Com.1, and 1.22, 1.98 and 16.11 times higher for Com.2. The above results proved that positive synergies had been formed on WAS hydrolysis under integration treatment $[11,14,33]$. And all FI of Com.2 were higher than that of Com.1, indicating that tyrosine protein-like substances presented the main abundant compounds of released matters, the same results could be found in previous literature [14]. As the protein-like substances in DOMs must be released from either EPSs or intracellular materials, and were relatively easy to be biodegraded $[42,45]$, the pretreatment methods applied, especially the integration method, were efficient for WAS hydrolysis, which closely related to WAS acidification.

The FI of LB-EPSs had the similar trend with DOMs (Fig. S3). This was also consistent with both the results provided in Section 3.2.1 and the previous studies, in which, the changes of protein-like sub- stances in LB-EPSs were similar with that in DOMs [11,14]. The possible reason might be that the LB-EPS layer, characterized by loose structure and rheological property, easily adsorbed the released organics from the intracellular and TB-EPS layer during the pretreatment period [14,33]. By contrast, compared with raw sludge, the FI of TB-EPSs all decreased significantly, especially in experimental tests. This was also consistent with both the results in section 3.2.1 and previous publications [11,14], in which, the FI decreased, when WAS was pretreated. The decrease of proteinlike substances in the TB-EPSs might be attributed to their solubilization and partial utilization by microorganisms [43], this was similar with previous literatures $[11,14,33,46]$, in which, though TB-EPS layer was tightly attached to the cell surface, extracellular polymeric organics in this layer were greatly released because of the disintegration effects caused by the pretreatment methods. Results above demonstrated that the release of protein-like substances in EPSs and/or cells of WAS were effectively ameliorated under integration treatment, which was beneficial to the followed acidification process.

\subsection{Kinetic modeling of WAS hydrolysis and acidification}

\subsubsection{Effects of pre-treatment on hydrolysis of WAS}

The level of soluble proteins and polysaccharides could be taken as an index to evaluate the efficiency of WAS hydrolysis [11], and the changes of SCOD mainly attributed to the contents of soluble proteins and polysaccharides $[11,19,47]$. Thus, released SCOD was used to evaluate the WAS hydrolysis under different conditions.

Fig. 5(a), (b) shows the hydrolysis kinetics of WAS under both sole RL and integration treatments. It was obvious that good agreement achieved between fitted and observed cumulative SCOD (Fig. S5a, b), with the strong correlation coefficients $\left(R^{2}: 0.9503-\right.$ $0.9967)$, small $\Delta q(\%)(1.95-9.37<10)$ and ARE $(\%)(0.038-$ $0.86<1$ ) (Table 2), indicating that WAS hydrolysis obeyed the PFO kinetics. A similar result had been reported by Feng et al. [48], hydrolysis of particulate COD in WAS was successfully presented by first-order kinetic model. With the RL levels increasing, the hydrolysis rate constant increased linearly in both sole RL and integration treatments (Fig. S4a). The highest hydrolysis rate constant was obtained in the $0.2 \mathrm{~g} \mathrm{RL} / \mathrm{g}$ TSS test, 4.06 times higher than control test. And it was further enhanced under combined treatment, which was 2.14 times higher than sole RL treatment. It was clear that the equilibrium SCFAs production had a strongly linear relationship with hydrolysis rate constant (Fig. S4b), demonstrated that improving WAS hydrolysis could enhance SCFAs production significantly.

\subsubsection{Kinetic modeling of SCFAs accumulation}

The kinetic studies were of great importance for gaining insight on SCFAs accumulation during the anaerobic fermentation. In this work, in order to evaluate the kinetics of SCFAs accumulations, both PFO and PSO models were fitted to interpret the experimental data. The fitted plots showed that PFO was much better than PSO model (Fig. 5(c)-(f)) and fitted cumulative SCFAs production from Eq. (1) (Fig. S5c, d) were more similar with those observed experimentally than that from Eq. (2) (Fig. S5e, f), indicating that SCFAs accumulations under all conditions were better fitted PFO than PSO kinetic model. Results above were supported by the statistical indices (Table 2). The correlation coefficient $\left(R^{2}\right), \Delta q(\%)$ and ARE (\%) were used for model comparison and goodness-of-fit evaluation for a given pretreatment method. It was obvious that $R^{2} \mathrm{~s}$ of the PFO model were more than that of the PSO model for all the tests. By contrast, $\Delta q(\%)$ s and ARE (\%)s of PFO model were all less than that of PSO model, suggested that PFO model fitted to the experimental data better. This was similar with previous literature, in which, the accumulation of SCFAs obeyed first-order kinetics 

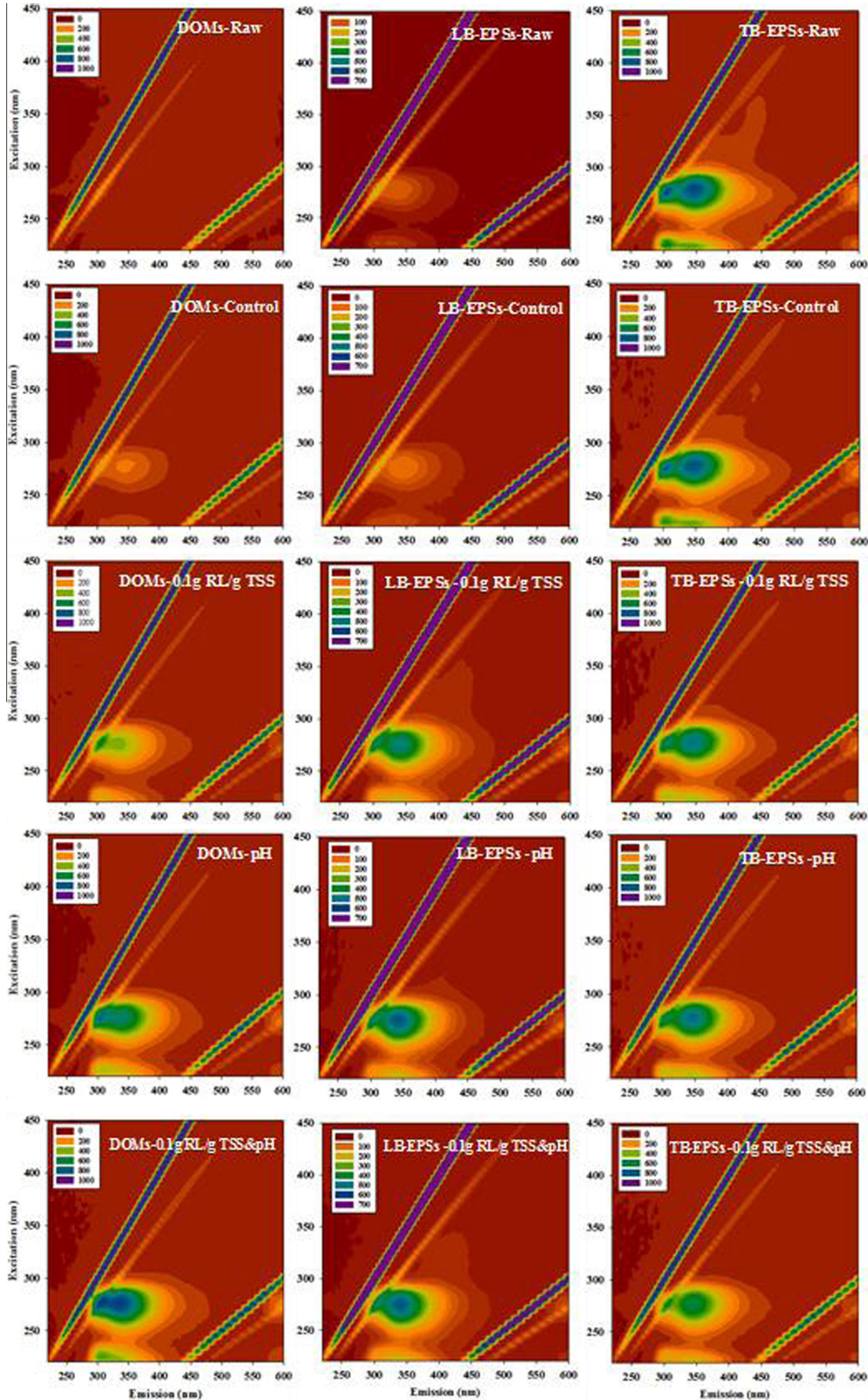

Fig. 4. EEM fluorescence spectra of DOMs, LB-EPSs, and TB-EPSs at 12-h fermentation time under different conditions. 

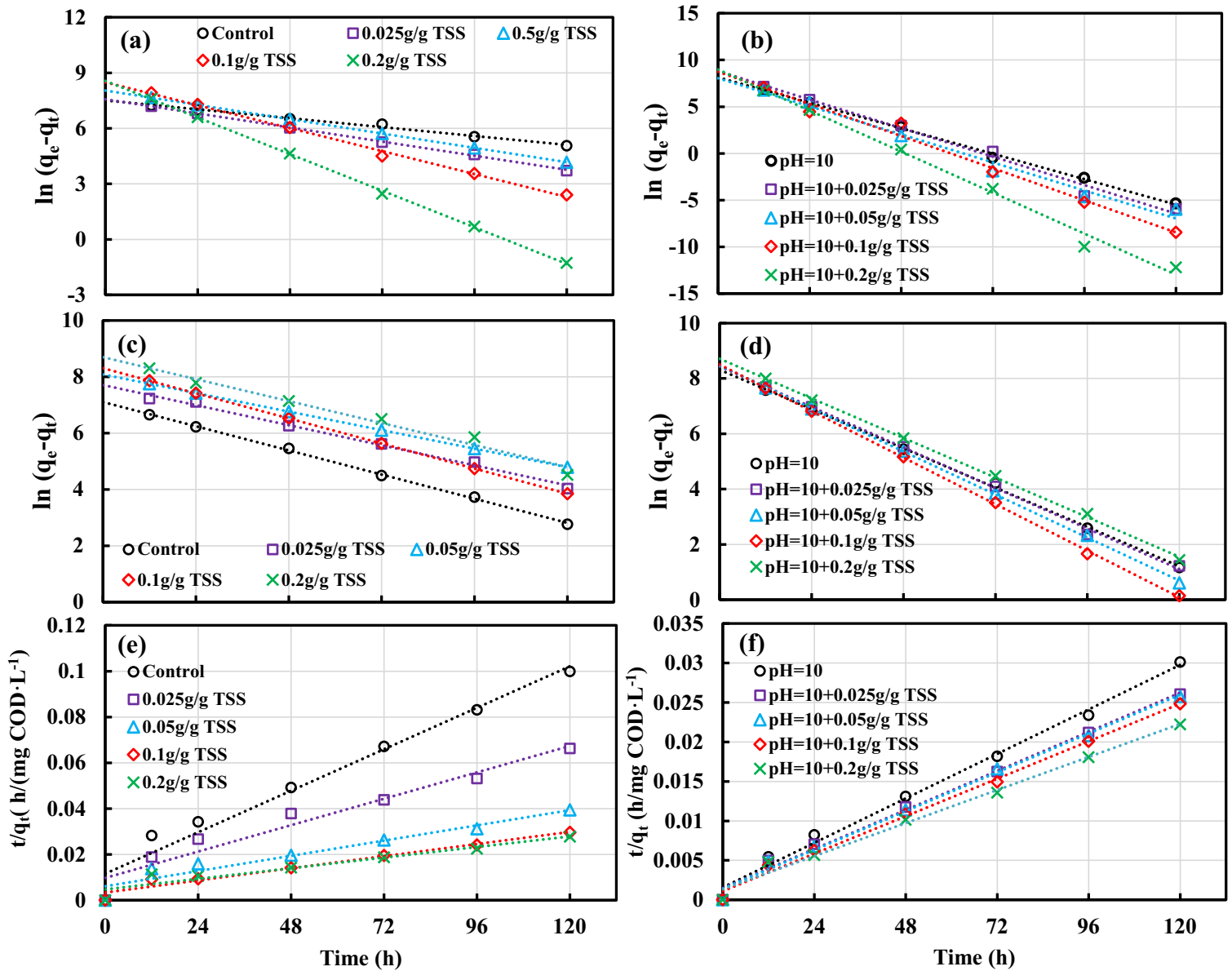

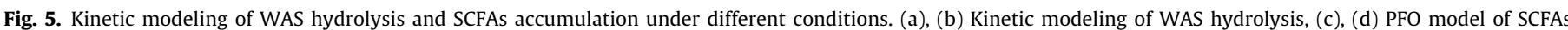
accumulation, and (e), (f) PSO model of SCFA s accumulation.

Table 2

Kinetic parameters for WAS hydrolysis and SCFAs accumulations under different conditions.

\begin{tabular}{|c|c|c|c|c|c|c|c|c|c|c|}
\hline No. & 1 & 2 & 3 & 4 & 5 & 6 & 7 & 8 & 9 & 10 \\
\hline \multicolumn{11}{|l|}{ WAS hydrolysis } \\
\hline$k_{1}\left(\mathrm{~h}^{-1}\right)$ & 0.0202 & 0.0318 & 0.0323 & 0.0520 & 0.0821 & 0.1134 & 0.1301 & 0.1330 & 0.1483 & 0.1753 \\
\hline$q_{e, \text { cal }}(\mathrm{mg} / \mathrm{L})$ & 2026 & 2198 & 3349 & 5380 & 5569 & 4429 & 4791 & 5315 & 6165 & 7222 \\
\hline$R^{2}$ & 0.9673 & 0.9741 & 0.9855 & 0.9858 & 0.9503 & 0.9951 & 0.9893 & 0.9698 & 0.9792 & 0.9967 \\
\hline$\Delta q(\%)$ & 9.32 & 7.62 & 6.87 & 5.42 & 9.37 & 2.43 & 3.65 & 6.13 & 5.08 & 1.95 \\
\hline ARE (\%) & 0.86 & 0.58 & 0.47 & 0.29 & 0.87 & 0.058 & 0.13 & 0.37 & 0.25 & 0.038 \\
\hline$q_{e, \exp }(\mathrm{mg} / \mathrm{L})$ & 1871 & 2204 & 3189 & 5481 & 5913 & 4393 & 4925 & 5654 & 6447 & 7262 \\
\hline \multicolumn{11}{|c|}{ Pseudo-first-order of SCFAs accumulation } \\
\hline$k_{1}\left(\mathrm{~h}^{-1}\right)$ & 0.0350 & 0.0269 & 0.0274 & 0.0372 & 0.0355 & 0.0594 & 0.0600 & 0.0647 & 0.0700 & 0.0632 \\
\hline$q_{e, \mathrm{cal}}(\mathrm{mg} \mathrm{COD} / \mathrm{L})$ & 1278 & 1986 & 3317 & 4155 & 4652 & 4088 & 4594 & 4624 & 4859 & 5426 \\
\hline$R^{2}$ & 0.9985 & 0.9909 & 0.9974 & 0.9957 & 0.9968 & 0.9951 & 0.9971 & 0.9965 & 0.9974 & 0.9934 \\
\hline$\Delta q(\%)$ & 1.48 & 6.71 & 2.52 & 4.91 & 6.52 & 3.43 & 2.29 & 2.17 & 1.99 & 3.73 \\
\hline ARE (\%) & 0.022 & 0.45 & 0.063 & 0.24 & 0.42 & 0.11 & 0.052 & 0.047 & 0.039 & 0.14 \\
\hline \multicolumn{11}{|c|}{ Pseudo-second-order of SCFAs accumulation } \\
\hline$k_{2}(\mathrm{~L} /(\mathrm{mg} \mathrm{COD} \cdot \mathrm{h}))$ & $5.52 \mathrm{E}-5$ & $2.58 \mathrm{E}-5$ & $1.45 \mathrm{E}-5$ & $1.18 \mathrm{E}-5$ & $0.83 \mathrm{E}-5$ & $2.50 \mathrm{E}-5$ & $2.67 \mathrm{E}-5$ & $2.86 \mathrm{E}-5$ & $3.64 \mathrm{E}-5$ & $2.90 \mathrm{E}-5$ \\
\hline$q_{e, \mathrm{cal}}(\mathrm{mg} \mathrm{COD} / \mathrm{L})$ & 1336 & 2086 & 3419 & 5086 & 5086 & 5086 & 5086 & 5086 & 5086 & 5086 \\
\hline$R^{2}$ & 0.9742 & 0.9649 & 0.9691 & 0.9801 & 0.9777 & 0.9806 & 0.9784 & 0.9780 & 0.9726 & 0.9545 \\
\hline$\Delta q(\%)$ & 11.59 & 11.83 & 16.24 & 22.13 & 20.42 & 23.37 & 13.59 & 13.06 & 10.91 & 13.90 \\
\hline ARE (\%) & 1.34 & 1.40 & 2.63 & 4.89 & 4.16 & 5.46 & 1.84 & 1.70 & 1.19 & 1.93 \\
\hline$q_{e, \exp }(\mathrm{mg} \mathrm{COD} / \mathrm{L})$ & 1264 & 1893 & 3146 & 4102 & 4392 & 4130 & 4654 & 4726 & 4891 & 5444 \\
\hline
\end{tabular}

[48]. Thus, PFO model was successfully built to present the SCFAs accumulation production.

3.4. $R$ L pretreatment integrated into alkaline anaerobic fermentation for exploiting internal CS to enhance nutrients removal in a WWTP

Our previous study had reported that RL pretreatment prior to anaerobic digestion is an economically attractive and environmen- tally favorable method for enhancing SCFAs production from WAS [21], this study revealed that further enhancement of SCFAs production could be achieved by RL pretreatment integrated into alkaline anaerobic fermentation of WAS. Compared with our previous work [21], some new findings have been discussed and concluded. Firstly, it was proved that more carbon recovery was increased under the new integrated condition using RL and alkaline (shown in Section 3.1.2). The more internal CS produced in situ in a WWTP, 


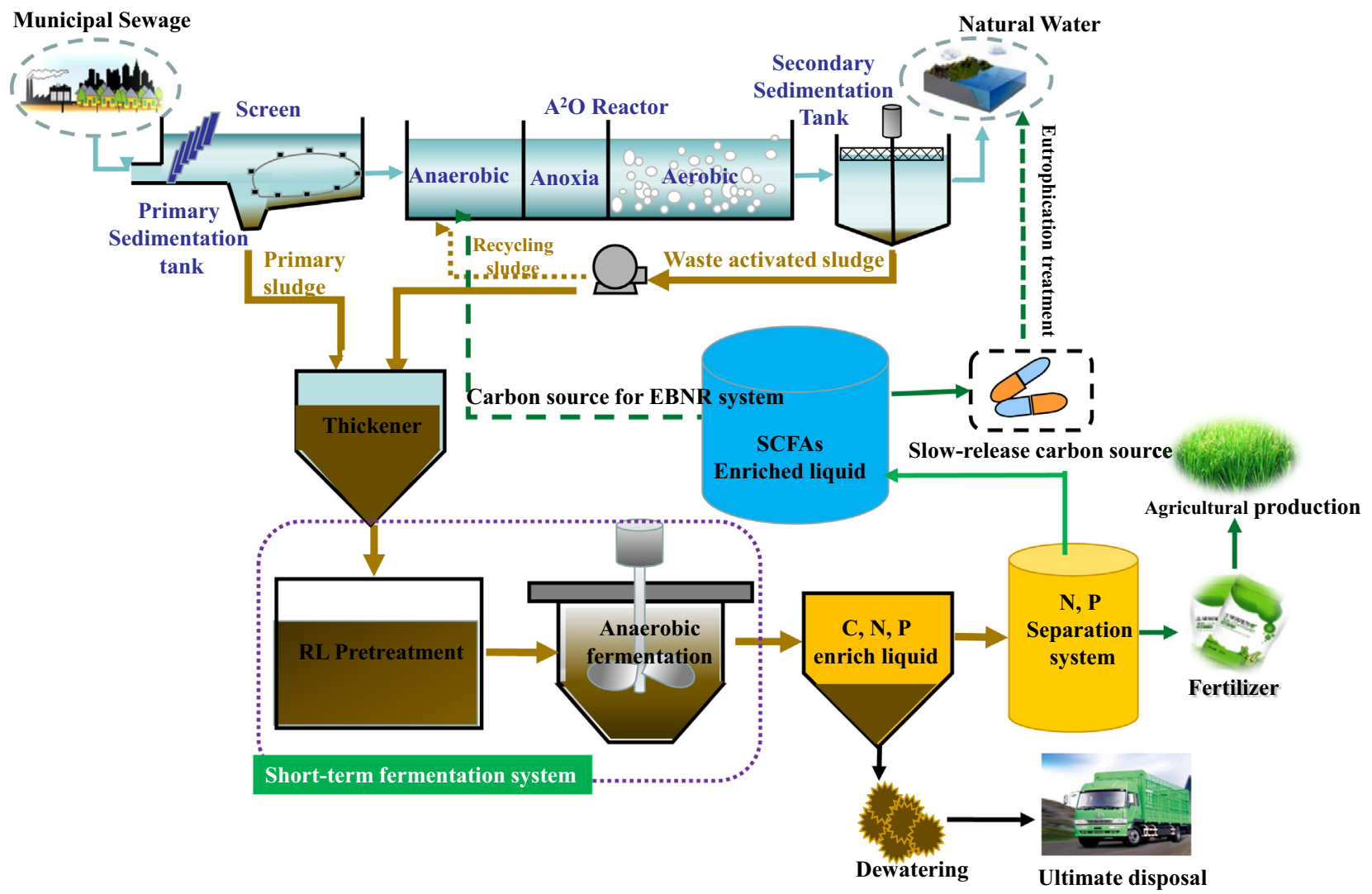

Fig. 6. The proposed RL integrated into alkaline anaerobic fermentation for enhancing SCFAs production to improve nutrients removal in a WWTP.

the less external CS for the operation of a WWTP needed $[5,6,18,26]$. Secondly, the efficient treatment led to a shortened fermentation time when using the new method. The maximum SCFAs accumulations achieved at 96-h (i.e., 4-day) or more fermentation time in the previous researches $[6,12,13,21,27]$, but it was reduced to 72-h (i.e., 3-day) in this study (shown in Section 3.1.1), which was attractive for both improving the efficiency of WAS disposal and preparing SCFAs from WAS to meet the CS demand of a WWTP $[6,12,18,27]$. Thirdly, the mechanisms of the enhanced SCFAs accumulations under either sole RL treatments or integrated treatments have been identified by investigating the role of EPSs on WAS solubilization (shown in Section 3.2) and kinetic modeling of WAS hydrolysis and acidification (shown in Section 3.3), which were not disclosed well in previous studies [12,21,27].

Currently, some methods had been applied to improve SCFAs production from WAS with anaerobic fermentation process, and Table S2 exhibits some typical methods reported in the previous publications. It was clear that, among these available methods, $\mathrm{pH}=10$ had been known as the most common way to enhance SCFAs production $[27,28]$. More interesting, SCFAs production could be further enhanced by adding RL into alkaline anaerobic fermentation process with a short-term fermentation time in this study. As well known, while using WAS as the substrate to produce internal CS in a WWTP, the SCFAs production should be maximized, in contrast, the input should be minimized. Unlike other pretreatment methods (e. g., ultrasonic), RL was a renewable chemical that could be in situ generated during the SCFAs production, proposed by our previous study [21], suggested that RL pretreatment integrated into alkaline anaerobic fermentation for SCFAs production from WAS was a potential and practical technology.

Therefore, a sustainable and economical technology was urgently needed to apply to enhance nutrient removal in WWTPs
(Fig. 6). And Tong et al. had reported that WAS alkaline fermentation liquid as the additional CS for municipal wastewater biological nitrogen and phosphorus removal, could obtain good performance, but the released nitrogen and phosphorus should be firstly separated from fermentation liquid [5]. Thus, the proposed concept in Fig. 6 may be potential and practical to reduce both operation cost and sludge production simultaneously of WWTPs.

\section{Conclusions}

The feasibility of short-term fermentation for enhancing SCFAs production from WAS with a novel proposed method, RL pretreatment integrated into alkaline (initial pH10) anaerobic fermentation, has been successfully investigated in this work. The main conclusions are: (1) positive synergies on anaerobic fermentation process had been formed under integration conditions. The maximum SCFAs production was increased to $378 \mathrm{mg}$ COD/g VSS at 72-h fermentation time, when WAS was pretreated by initial $\mathrm{pH}$ 10 and RL dosage $0.2 \mathrm{~g} / \mathrm{g}$ TSS. (2) Compared with control, initial $\mathrm{pH} 10$ and sole RL methods, the integration method performed best to release intracellular and/or extracellular constituents from the cells and/or EPSs to suspension, and hydrolysis rate was 2.14 times higher than that of sole RL treatment. (3) The PFO model was successfully built to present the SCFAs accumulation production. (4) RL pretreatment integrated into alkaline anaerobic fermentation was an attractive technology for enhancing sustainable CS (SCFAs) production from WAS in situ in a WWTP.

\section{Acknowledgements}

This research was supported by National Science Foundation for Distinguished Young Scholars of China (Grant No. 51225802), by 
National Natural Science Foundation of China (NSFC, No. 51578534), by the Major Science and Technology Program for Water Pollution Control and Treatment of China (No. 2014ZX07204-005), by "Hundred Talents Program" of the Chinese Academy of Sciences, and by Project 135 of Chinese Academy of Sciences (No. YSW2013B06), and by International S\&T cooperation program (No. S2015GR1012).

\section{Appendix A. Supplementary data}

Supplementary data associated with this article can be found, in the online version, at http://dx.doi.org/10.1016/j.cej.2016.01.033.

\section{References}

[1] P. Kampas, S.A. Parsons, P. Pearce, S. Ledoux, P. Vale, J. Churchley, E. Cartmell, Mechanical sludge disintegration for the production of carbon source for biological nutrient removal, Water Res. 41 (2007) 1734-1742.

[2] J. Guerrero, C. Taya, A. Guisasola, J.A. Baeza, Glycerol as a sole carbon source for enhanced biological phosphorus removal, Water Res. 46 (2012) 29832991.

[3] B. Ma, Y. Peng, Y. Wei, B. Li, P. Bao, Y. Wang, Free nitrous acid pretreatment of wasted activated sludge to exploit internal carbon source for enhanced denitrification, Bioresour. Technol. 179 (2015) 20-25.

[4] X. Wang, Y. Zhang, T. Zhang, J. Zhou, M. Chen, Waste activated sludge fermentation liquid as carbon source for biological treatment of sulfide and nitrate in microaerobic conditions, Chem. Eng. J. 283 (2016) 167-174.

[5] J. Tong, Y.G. Chen, Recovery of nitrogen and phosphorus from alkaline fermentation liquid of waste activated sludge and application of the fermentation liquid to promote biological municipal wastewater treatment, Water Res. 43 (2009) 2969-2976.

[6] N. Frison, S. Di Fabio, C. Cavinato, P. Pavan, F. Fatone, Best available carbon sources to enhance the via-nitrite biological nutrients removal from supernatants of anaerobic co-digestion, Chem. Eng. J. 215 (2013) 15-22.

[7] G. Yang, G.M. Zhang, H.C. Wang, Current state of sludge production, management, treatment and disposal in China, Water Res. 78 (2015) 60-73.

[8] C. Wu, G.M. Zhang, P.Y. Zhang, C.C. Chang, Disintegration of excess activated sludge with potassium permanganate: feasibility, mechanisms and parameter optimization, Chem. Eng. J. 240 (2014) 420-425.

[9] M.S. Ak, M. Muz, O.T. Komesli, C.F. Gökçay, Enhancement of bio-gas production and xenobiotics degradation during anaerobic sludge digestion by ozone treated feed sludge, Chem. Eng. J. 230 (2013) 499-505.

[10] M. Pijuan, Q.L. Wang, L. Ye, Z.G. Yuan, Improving secondary sludge biodegradability using free nitrous acid treatment, Bioresour. Technol. 116 (2012) 92-98.

[11] C.X. Yang, W.Z. Liu, Z.W. He, S. Thangavel, L. Wang, A.J. Zhou, A.J. Wang, Freezing/thawing pretreatment coupled with biological process of thermophilic Geobacillus sp. G1: acceleration on waste activated sludge hydrolysis and acidification, Bioresour. Technol. 175 (2015) 509-516.

[12] X.F. Huang, C.M. Shen, J. Liu, L.J. Lu, Improved volatile fatty acid production during waste activated sludge anaerobic fermentation by different biosurfactants, Chem. Eng. J. 264 (2015) 280-290.

[13] S. Jiang, Y.G. Chen, Q. Zhou, Effect of sodium dodecyl sulfate on waste activated sludge hydrolysis and acidification, Chem. Eng. J. 132 (2007) 311-317.

[14] C.X. Yang, A.J. Zhou, Z.W. He, L. Jiang, Z.C. Guo, A.J. Wang, W.Z. Liu, Effects of ultrasonic-assisted thermophilic bacteria pretreatment on hydrolysis, acidification, and microbial communities in waste-activated sludge fermentation process, Environ. Sci. Pollut. Res. 22 (2015) 9100-9109.

[15] H.B. Liu, H. Xiao, B. Yin, Y.P. Zu, H. Liu, B. Fu, H.J. Ma, Enhanced volatile fatty acid production by a modified biological pretreatment in anaerobic fermentation of waste activated sludge, Chem. Eng. J. 284 (2016) 194-201.

[16] H.X. Bao, L. Jiang, C.X. Chen, C.X. Yang, Z.W. He, Y.D. Feng, W.W. Cai, W.Z. Liu, A. J. Wang, Combination treatment of ultrasound and Fenton for improving hydrolysis and acidification of waste activated sludge, RSC Adv. 5 (2015) $48468-48473$

[17] X. Yang, C.L. Wan, D.J. Lee, M.A. Du, X.L. Pan, F. Wan, Continuous volatile fatty acid production from waste activated sludge hydrolyzed at $\mathrm{pH} 12$, Bioresour. Technol. 168 (2014) 173-179.

[18] L.N. Pang, J.R. Ni, X.Y. Tang, Q. Chen, Short-cut waste activated sludge fermentation and application of fermentation liquid to improve heterotrophic aerobic nitrogen removal by Agrobacterium sp. LAD9, Chem. Eng. J. 259 (2015) 911-917.

[19] Q.L. Wang, L. Ye, G.M. Jiang, P.D. Jensen, D.J. Batstone, Z.G. Yuan, Free nitrous acid (FNA)-based pretreatment enhances methane production from waste activated sludge, Environ. Sci. Technol. 47 (2013) 11897-11904.

[20] S. Kavitha, S.A. Kumar, S. Kaliappan, J.I.T. Yeom, J.R. Banu, Achieving profitable biological sludge disintegration through phase separation and predicting its anaerobic biodegradability by non linear regression model, Chem. Eng. J. 279 (2015) 478-487.
21] A.J. Zhou, C.X. Yang, Z.C. Guo, Y.N. Hou, W.Z. Liu, A.J. Wang, Volatile fatty acids accumulation and rhamnolipid generation in situ from waste activated sludge fermentation stimulated by external rhamnolipid addition, Biochem. Eng. J. 77 (2013) 240-245.

[22] X. Yang, M.A. Du, D.J. Lee, C.L. Wan, L.N. Zheng, G.Y. Li, J.S. Chang, Enhanced production of volatile fatty acids (VFAs) from sewage sludge by $\beta$-cyclodextrin, Bioresour. Technol. 110 (2012) 688-691.

[23] A.V. Ebenezer, P. Arulazhagan, S.A. Kumar, I.T. Yeom, J.R. Banu, Effect of deflocculation on the efficiency of low-energy microwave pretreatment and anaerobic biodegradation of waste activated sludge, Appl. Energy 145 (2015) 104-110.

[24] Y. Feng, Y. Zhang, S. Chen, X. Quan, Enhanced production of methane from waste activated sludge by the combination of high-solid anaerobic digestion and microbial electrolysis cell with iron-graphite electrode, Chem. Eng. J. 259 (2015) 787-794.

[25] R.U. Rani, S. Kaliappan, S.A. Kumar, J.R. Banu, Combined treatment of alkaline and disperser for improving solubilization and anaerobic biodegradability of dairy waste activated sludge, Bioresour. Technol. 126 (2012) 107-116.

[26] W.S. Lee, A.S.M. Chua, H.K. Yeoh, G.C. Ngoh, A review of the production and applications of waste-derived volatile fatty acids, Chem. Eng. J. 235 (2014) 8399.

[27] H.Y. Yuan, Y.G. Chen, H.X. Zhang, S. Jiang, Q. Zhou, G.W. Gu, Improved bioproduction of short-chain fatty acids (SCFAs) from excess sludge under alkaline conditions, Environ. Sci. Technol. 40 (2006) 2025-2029.

[28] J.W. Zhao, D.B. Wang, X.M. Li, Q. Yang, H.B. Chen, Y. Zhong, G.M. Zeng, Free nitrous acid serving as a pretreatment method for alkaline fermentation to enhance short-chain fatty acid production from waste activated sludge, Water Res. 78 (2015) 111-120.

[29] X.Y. Li, S.F. Yang, Influence of loosely bound extracellular polymeric substances (EPS) on the flocculation, sedimentation and dewaterability of activated sludge, Water Res. 41 (2007) 1022-1030.

[30] X.M. Liu, G.P. Sheng, H.W. Luo, F. Zhang, S.J. Yuan, J. Xu, R.J. Zeng, J.G. Wu, H.Q Yu, Contribution of extracellular polymeric substances (EPS) to the sludge aggregation, Environ. Sci. Technol. 44 (2010) 4355-4360.

[31] G. Zhen, X. Lu, Y.Y. Li, Y. Liu, Y. Zhao, Influence of zero valent scrap iron (ZVSI) supply on methane production from waste activated sludge, Chem. Eng. J. 263 (2015) 461-470

[32] L.L. Yan, Y. Liu, Y. Wen, Y. Ren, G.X. Hao, Y. Zhang, Role and significance of extracellular polymeric substances from granular sludge for simultaneous removal of organic matter and ammonia nitrogen, Bioresour. Technol. 179 (2015) 460-466

[33] A.J. Zhou, C.X. Yang, F.Y. Kong, D.D. Liu, Z.B. Chen, N.Q. Ren, A.J. Wang, Improving the short-chain fatty acids production of waste activated sludge stimulated by a bi-frequency ultrasonic pretreatment, J. Environ. Biol. 34 (2013) 381-389.

[34] L. Wang, W.Z. Liu, L.L. Kang, C.X. Yang, A.J. Zhou, A.J. Wang, Enhanced biohydrogen production from waste activated sludge in combined strategy of chemical pretreatment and microbial electrolysis, Int. J. Hydrogen Energy 39 (2014) 11913-11919.

[35] X.Y. Yang, B. Al-Duri, Kinetic modeling of liquid-phase adsorption of reactive dyes on activated carbon, J. Colloid Interface Sci. 287 (2005) 25-34.

[36] Y.M. Li, J. Wang, A. Zhang, L. Wang, Enhancing the quantity and quality of short-chain fatty acids production from waste activated sludge using $\mathrm{CaO} 2$ as an additive, Water Res. 83 (2015) 84-93.

[37] A. Rahmani-Sani, A. Hosseini-Bandegharaei, S.H. Hosseini, K. Kharghani, H Zarei, A. Rastegar, Kinetic, equilibrium and thermodynamic studies on sorption of uranium and thorium from aqueous solutions by a selective impregnated resin containing carminic acid, J. Hazard. Mater. 286 (2015) $152-163$.

[38] S.J. Allen, G. Mckay, J.F. Porter, Adsorption isotherm models for basic dye adsorption by peat in single and binary component systems, J. Colloid Interface Sci. 280 (2004) 322-333.

[39] A.M. El-Kamash, A.A. Zaki, M.A. El Geleel, Modeling batch kinetics and thermodynamics of zinc and cadmium ions removal from waste solutions using synthetic zeolite A, J. Hazard. Mater. 127 (2005) 211-220.

[40] Y.G. Chen, A.A. Randall, T. McCue, The efficiency of enhanced biological phosphorus removal from real wastewater affected by different ratios of acetic to propionic acid, Water Res. 38 (2004) 27-36.

[41] G.P. Sheng, H.Q. Yu, Characterization of extracellular polymeric substances of aerobic and anaerobic sludge using three-dimensional excitation and emission matrix fluorescence spectroscopy, Water Res. 40 (2006) 12331239.

[42] L. Lu, D.F. Xing, B.F. Liu, N.Q. Ren, Enhanced hydrogen production from waste activated sludge by cascade utilization of organic matter in microbial electrolysis cells, Water Res. 46 (2012) 1015-1026.

[43] B.J. Ni, F. Fang, W.M. Xie, M. Sun, G.P. Sheng, W.H. Li, H.Q. Yu, Characterization of extracellular polymeric substances produced by mixed microorganisms in activated sludge with gel-permeating chromatography, excitation-emission matrix fluorescence spectroscopy measurement and kinetic modeling, Water Res. 43 (2009) 1350-1358.

[44] Y.X. Zhang, P.Y. Zhang, J.B. Guo, W.F. Ma, L.P. Xiao, Spectroscopic analysis and biodegradation potential study of dissolved organic matters in sewage sludge treated with high-pressure homogenization, Bioresour. Technol. 135 (2013) 616-621. 
[45] N.P. Sanchez, A.T. Skeriotis, C.M. Miller, Assessment of dissolved organic matter fluorescence PARAFAC components before and after coagulationfiltration in a full scale water treatment plant, Water Res. 47 (2013) 1679 1690.

[46] L. Zhu, H.Y, Oi, Y, Kong Y.W. Yu, X.Y. Xu, Component analysis of extracellula polymeric substances (EPS) during aerobic sludge granulation using FTIR and 3D-EEM technologies, Bioresour. Technol. 124 (2012) 455-459.
[47] Q.L. Wang, G.M. Jiang, L. Ye, Z.G. Yuan, Enhancing methane production from waste activated sludge using combined free nitrous acid and heat pretreatment, Water Res. 63 (2014) 71-80.

[48] L.Y. Feng, Y.Y. Yan, Y.G. Chen, Kinetic analysis of waste activated sludge hydrolysis and short-chain fatty acids production at pH 10, J. Environ. Sci. 21 (2009) 589-594. 